2019-03-20

\title{
Cadmium pigments in consumer products and their health risks
}

\author{
Turner, Andrew
}

http://hdl.handle.net/10026.1/13186

10.1016/j.scitotenv.2018.12.096

Science of the Total Environment

Elsevier

All content in PEARL is protected by copyright law. Author manuscripts are made available in accordance with publisher policies. Please cite only the published version using the details provided on the item record or document. In the absence of an open licence (e.g. Creative Commons), permissions for further reuse of content should be sought from the publisher or author. 


\section{Cadmium pigments in consumer products and their health risks}

4

5

6

7

8 9

10

11

12
Andrew Turner*

School of Geography, Earth and Environmental Sciences, Plymouth University, Drake Circus, Plymouth PL4 8AA, UK

*Corresponding author

e-mail: aturner@plymouth.ac.uk

\section{Accepted $7^{\text {th }}$ December 2018}

Embargoed until $7^{\text {th }}$ December 2020 (24 months) 
Abstract

Cadmium is a toxic heavy metal that has been increasingly regulated over the past few decades. The main exposure routes for the general public are the consumption of certain foods and the inhalation of cigarette smoke. However, additional exposure may occur through the current and historical use of the metal in consumer products. In this paper, the uses of $\mathrm{Cd}$ in consumer goods are reviewed, with the focus on brightly-coloured Cd sulphide and sulphoselenide pigments, and measurements of $\mathrm{Cd}$ in historical and contemporary products ascertained by XRF are reported. Cadmium is encountered across a wide range of contemporary plastic products, mainly because of the unregulated recycling of electronic waste and polyvinyl chloride. However, concentrations are generally low $\left(<100 \mu \mathrm{g} \mathrm{g}^{-1}\right)$, conforming with current limits and posing minimal risk to consumers. Of greater concern is high concentrations of pigmented $\mathrm{Cd}$ (up to $2 \%$ by weight) in old products, and in particular children's toys that remain in circulation. Here, tests conducted suggest that $\mathrm{Cd}$ migration in some products exceeds the Toy Safety Directive limit of $17 \mu \mathrm{g} \mathrm{g}^{-1}$ by an order of magnitude. The principal current use of $\mathrm{Cd}$ pigments is in ceramic products where the metal is encapsulated and overglazed. Leaching tests on new and secondhand items of hollowware indicate compliance with respect to the current $\mathrm{Cd}$ limit of $300 \mu \mathrm{g} \mathrm{L}^{-1}$, but that non-compliance could occur for items of earthenware or damaged articles should a proposed limit of $5 \mu \mathrm{g} \mathrm{L}^{-1}$ be introduced. The greatest consumer risk identified is the use of $\mathrm{Cd}$ pigments in the enamels of decorated drinking glasses. Thus, while décor is restricted to the exterior, any enamel within the lip area is subject to ready attack from acidic beverages because the pigments are neither encapsulated nor overglazed. Decorated glass bottles do not appear to represent a direct health hazard but have the propensity to contaminate recycled glass products. It is recommended that decorated glassware is better regulated and that old, brightly-coloured toys are treated cautiously.

Keywords: cadmium; plastics; ceramics; glassware; pigments; health 


\section{Introduction}

Cadmium ( $\mathrm{Cd}$ ) is a cumulative toxin that is associated with kidney disease and that has effects on the skeletal and respiratory systems (Larsson and Wolk, 2015). The heavy metal and its compounds are also classified as known or probable, non-threshold human carcinogens by several regulatory agencies, with data linking occupational exposure to lung cancer (Waalkes, 2003). Cadmium is widely distributed in the environment at concentrations that are naturally low but that have increased through human activities like smelting and refining of non-ferrous metals, fossil fuel combustion, phosphate fertilizer manufacture, recycling of metal and electronic waste, and municipal waste incineration (WHO, 2010). Because of its high rates of soil-plant and water-organism transfer, the general population is exposed to $\mathrm{Cd}$ principally through inhalation of cigarette smoke and intake of certain cereals, vegetables and seafoods (Satarug, 2012). Based on available epidemiological data, the European Food Standards Authority has established a tolerable weekly intake of dietary Cd of 2.5 $\mu \mathrm{gg}^{-1}$ body weight (EFSA panel on contaminants in the food chain, 2011).

Cadmium as a metal, alloy or compound has had a variety of uses in consumer products, including rechargeable batteries, items of jewellery and plastic goods, which pose an additional potential source of human exposure, mainly through direct and indirect ingestion and in particular to children. The risks are often difficult to quantify but based on our current and growing understanding of the biological effects of $\mathrm{Cd}$ and its persistence in the human body, a precautionary principle is recommended (Nawrot et al., 2010). Accordingly, various regulations and directives have been introduced during the past three decades to protect consumers and the environment, examples of which are defined in Table 1.

In this paper, the uses of cadmium and its compounds in products amenable to the consumer are reviewed, with the focus on the occurrence of cadmium-based sulphide and sulphoselenide pigments used to colour plastics, paints and ceramics, and where the metal is likely to appear in a wide range of products where it is not necessarily expected or desired. New and published data relating to the concentrations of $\mathrm{Cd}$ (and, for sulphoselenides, Se) in polymeric-based consumer products or components thereof and gained through portable $x$-ray fluorescence (XRF) analysis by the author's research group over the past few years are described and compared with values defined by current and historical regulations. Data are also presented on the migration or extraction of $\mathrm{Cd}$ from various products where regulations and standard tests are defined or implied.

\section{Uses of cadmium in consumer products and relevant regulations}




\subsection{Electronics}

In Cd-based sealed, rechargeable batteries, the metal serves as the cathode and $\mathrm{NiOOH}$ as the anode in a potassium hydroxide electrolyte. The two electrodes and associated separators are rolled together into a cylindrical configuration that is contained by a can, providing a nominal electromotive force of $1.2 \mathrm{~V}$. Although such cells have good life spans, and are reliable, versatile and able to deliver their full capacity at high discharge rates, environmental concerns and newer, superior alternatives have meant that the use of cadmium-based batteries has declined significantly over the past two decades. Within the European Union, new Ni-Cd batteries are now only permitted as replacements for specialist equipment (European Parliament and of the Council, 2006) that, as of December 2016, excludes power tools (BIS, 2015a).

In electronics, $\mathrm{Cd}$ and its compounds are used as contacts for switches and relays, as colourants in glass and filter glass and in printing inks applied to glass, as alloys in solder joints, in film pastes, and in colour-converting light emitting diodes (BIS, 2011). The Restriction of the Use of Certain Hazardous Substances in Electrical and Electronic Equipment (RoHS) Regulations have limited the concentrations of $\mathrm{Cd}$ in any component or subassembly of new electrical and electronic equipment, including plastic casings or insulation, to $100 \mu \mathrm{g} \mathrm{g}^{-1}$ (European Parliament and Council, 2003), while the Institute of Electrical and Electronics Engineers Standard 1680 regarding personal computer products states that $\mathrm{Cd}$ shall not exceed $50 \mu \mathrm{g} \mathrm{g}^{-1}$ in homogeneous materials unless demonstrably present through recyclate (IEEE, 2006).

\subsection{Jewellery}

Items of jewellery, and in particular cheap replicas that target children, have come under increasing scrutiny over the past few years because of potentially high concentrations of alloyed $\mathrm{Cd}$. For instance, Weidenhamer et al. (2011) found Cd concentrations among several hundred charms, pendants, bracelets and other embellishments sourced in the US that exceeded $10 \%$ by weight, with quantities accessible to simulated saliva and dilute $\mathrm{HCl}$ that were highly variable but that exceeded $2000 \mu \mathrm{g}$ and 20,000 $\mu \mathrm{g}$, respectively, in some cases. Guney and Zagury (2014) found Cd concentrations up to $37 \%$ by weight in various items of jewellery sourced in Canada with bioaccessible concentrations of up to $165 \mu \mathrm{g} \mathrm{g}^{-1}$ derived from an in vitro gastrointestinal protocol. It is suspected that more stringent controls on lead in consumer products, coupled with the diminishing value of $\mathrm{Cd}$ as $\mathrm{Ni}-\mathrm{Cd}$ batteries are phased out, has led to an increased production of $\mathrm{Cd}$ based jewellery in China for exportation (Olesen and Hoshiko, 2010). The EU has since prohibited the use of $\mathrm{Cd}$ in metallic parts of jewellery, imitation jewellery and hair accessories according to 
Regulation No. 494/2011 on cadmium (European Union, 2011), with a maximum permissible concentration of $100 \mu \mathrm{g} \mathrm{g}^{-1}$ for items placed on the market after 2012.

\subsection{Polyvinyl chloride}

Cadmium was used in the form of a laurate or stearate as a stabiliser in polyvinyl chloride (PVC), together with salts of barium and lead. Being heat-stable and resistant to ultra violet light, $\mathrm{Cd}$-based stabilisers were used extensively in outdoor plastics like window frames, doors and drainage systems, but were also used for furniture, office equipment, apparel and clothing and wiring insulation (European Chemicals Agency, 2013a). The European PVC industry began to voluntarily phase out Cd-based stabilisers in 2001 before the EC prohibited their use in 2011 according to EU Regulation 494/2011 (with the exception of recycled PVC in some construction plastics where Cd is permitted at concentrations below $1000 \mu \mathrm{g} \mathrm{g}^{-1}$; European Union, 2011).

\subsection{Cadmium pigments}

As colourants, and because of their heat stability, chemical resistance, opacity, light fastness and tinting strength, sulphides of $\mathrm{Cd}$ have been used extensively by the plastics and ceramics industries (Wilson et al., 1982). Estimates suggest that the annual consumption of cadmium-based pigments peaked at around 6000 tonnes in 1975, with the majority ( 90\%) used in plastics. Production has been shrinking since because of both health and environmental concerns (European Chemicals Agency, 2012), with information reported as of February 2018 indicating that current annual production lies somewhere between 10 and 100 tonnes (Chemsec, 2018). Cadmium sulphide itself, CdS, is a brilliant yellow (C.I. Pigment Yellow 37) but $\mathrm{Zn}$ (and sometimes $\mathrm{Hg}$ ) as a cation and selenide as an anion serve as exchangeable ions to effect different colour shadings. Specifically, cadmium zinc sulphide, $(\mathrm{Cd}, \mathrm{Zn}) \mathrm{S}$ (C.I. Pigment Yellow 35), is a greenish yellow, and cadmium sulphoselenide, $\mathrm{Cd}(\mathrm{S}, \mathrm{Se})$, may be orange (C.I. Pigment Orange 20) or red (C.I. Pigment Red 108). These pigments are produced by dissolution of $\mathrm{Cd}$ metal, with or without $\mathrm{Zn}$, in mineral acid and subsequent precipitation with sulphide or selenide; the filtered precipitate is then calcined in the absence of oxygen at around $600-700^{\circ} \mathrm{C}$ before being milled and blended (Pfaff, 2017).

Early risk assessments suggested that $\mathrm{Cd}$ sulphide pigments posed little risk to humans and the environment because of their encapsulation by the polymeric matrix and extremely low solubilities $\left(K_{\mathrm{sp}, \mathrm{CdS}}=7.94 \times 10^{-27} ; K_{\mathrm{sp}, \mathrm{CdSe}}=6.31 \times 10^{-36}\right)$ (Wilson et al., 1982; Kawasaki et al., 2004). However, possible instability in the presence of acids, coupled with such widespread usage and potential consumer exposure from a variety of sources, have resulted in calls for a re-evaluation of their 
profiles (European Chemicals Agency, 2012). Significantly, recent research has highlighted the environmental significance of the photosensitivities of $\mathrm{CdS}$ and CdSe pigments (band gaps of 2.5 and $1.8 \mathrm{eV}$, respectively), whose oxidised products (cadmium sulphate and cadmium selenite) are considerably more soluble and bioavailable (Liu et al., 2017).

\subsubsection{Cadmium pigments in plastics}

Cadmium pigments were commonly employed to colour a variety of consumer plastics but were particularly favourable where high processing temperatures and high-performance products precluded the use of organic pigments (e.g. acrylonitrile butadiene styrene, polycarbonates and high-density polyethylene; Wilson et al., 1982). Between 0.05 and $1.5 \%$ of $\mathrm{Cd}$ pigment by weight was normally added to plastic as a powder and with a grain size in the range 1 to $3.5 \mu \mathrm{m}$. Being dispersed in the matrix, the pigment exerts very little effect on the physical properties of the plastic, like tensile strength and impact resistance (Scoullos et al., 2001).

Restrictions on the use of Cd pigments in plastics were introduced by individual nations in the 1980s and currently the EU prohibits the use of $\mathrm{Cd}$ in most consumer products according to Regulation 494/2011 (European Union, 2011). Specifically, Cd concentrations are limited to $100 \mu \mathrm{g} \mathrm{g}^{-1}$ in products placed on the market after 2012, with the exception of articles coloured for safety reasons. With the exception of recycled pallets and crates in closed loop schemes, Cd is also restricted to 100 $\mu \mathrm{g} \mathrm{g}^{-1}$ in plastics used for non-food packaging according to the European packing and packing waste regulations (European Parliament and Council of the EU, 1994; BIS, 2015b). (Note that there have been recent suggestions that $\mathrm{Cd}$ should be banned outright from all plastic products; European Chemicals Agency, 2013a.)

Migratable Cd (in pigmented or any other form) is restricted in children's toys according to the European Union Toy Safety Directive. The original Directive (88/378/EEC; Council of the European Communities, 1988) stipulated limits for $\mathrm{Cd}$ and other toxic elements in a range of toys that could be extracted by $0.07 \mathrm{M} \mathrm{HCl}$ at $37{ }^{\circ} \mathrm{C}$ according to the European Standard, EN 71-3 (BSI, 1995). The maximum migratable concentration for $\mathrm{Cd}$ was set at $50 \mathrm{\mu g} \mathrm{g}^{-1}$ but an amended Directive that applied to products placed on the market from July 2013 provided revised limits for more specific matrices, with the maximum concentration of Cd in "scraped-off" materials, including plastics, now set at $17 \mu \mathrm{g} \mathrm{g}^{-1}$ (European Parliament and Council of the EU, 2009).

\subsubsection{Cadmium pigments in ceramics and glassware}

With restrictions on the use of $\mathrm{Cd}$ compounds in plastics, their principal, remaining use has been as decorative pigments for ceramicware and enamels for glass and porcelain products. Here, pigments 
are partly dissolved into a matrix medium that adheres to the product. In ceramicware, the decoration is glazed and fired at high temperature, in theory sealing any toxic compounds and eliminating attack from food or washing solutions, while on glassware, the decorated product is fired at a lower temperature. Cadmium sulphoselenides are one of only a few pigments that provide an intense red colour but the compounds are not inherently stable at temperatures required for firing ceramicware $\left(750\right.$ to $\left.1450^{\circ} \mathrm{C}\right)$. This problem has been circumvented by encapsulating the pigments in zircon, and mixing occluded sulphoselenides with other non-cadmium-based pigments is now able to produce a wide range of colour shades (Lehman, 2002).

European regulations do not prohibit the use of Cd-based pigments for decorative purposes in foodcontact ceramicware, but relate to the concentrations of $\mathrm{Cd}$ extracted by dilute acetic acid according to Directive 84/500/EEC (Council of the European Communities, 1984); the approach is effectively the same as that defined by the ASTM for standard test C738-94 (ASTM, 2016). Thus, cleaned articles are filled with test simulant, covered with opaque glass and left at $22 \pm 2^{\circ} \mathrm{C}$ for 24 hours. For shallow articles (flat-ware: internal depth $<25 \mathrm{~mm}$ ), the limit for $\mathrm{Cd}$ release is $70 \mu \mathrm{g} \mathrm{dm}^{-2}$, while for hollow-ware and cooking ware, limits are 300 and $100 \mu \mathrm{g} \mathrm{L}^{-1}$, respectively. However, evolving knowledge about the accumulation and toxicity of $\mathrm{Cd}$ and World Health Organization drinking water guidelines of just $3 \mu \mathrm{g} \mathrm{L}^{-1}$ (WHO, 2011) have resulted in calls for these limits to be lowered significantly. Accordingly, a recent European Commission report has stipulated "discussing starting values" of $1 \mu \mathrm{g} \mathrm{dm}{ }^{-2}$ for flat-ware and $5 \mu \mathrm{g} \mathrm{L}^{-1}$ and $1.9 \mu \mathrm{g} \mathrm{L}^{-1}$ for hollow-ware and cooking ware, respectively (Beldì et al., 2016).

California's Safe Drinking Water and Toxic Enforcement Act of 1986 (Proposition 65) has more stringent guidelines on the $\mathrm{Cd}$ content of ceramics designed for food and beverages (Office of Environmental Health Hazard Assessment, 2016). Thus, a prominently placed warning is required on a product sold or distributed within the state if external decorations exceed limit values; specifically, areas exclusive of the lip (within $20 \mathrm{~mm}$ of and including the rim) have a limit of $4800 \mu \mathrm{g} \mathrm{g}^{-1}$ total Cd while the lip area itself has a limit of $800 \mu \mathrm{g} \mathrm{g}^{-1} \mathrm{Cd}$. A product may evade warning if it is shown to release less than $7.92 \mathrm{mg} \mathrm{L}^{-1} \mathrm{Cd}$ in dilute acetic acid according to a modified ASTM test only if it is not designed for children.

Less clear and regulated are the quantities and migratabilities of $\mathrm{Cd}$ used in the coloured enamels on glassware. Despite not being decorated internally, the risks of exposure may be greater on glass articles because the pigments are over-glazed and subject to greater deterioration through abrasion during use and storage and more readily exposed to chemical attack from foodstuffs and washing solutions (Turner, 2018a). With respect to California's Proposition 65, the Cd content of decorated 
glass articles appears to be subject to the same limits as ceramics $\left(4800 \mu \mathrm{g} \mathrm{g}^{-1}\right.$ exclusive of the lip area and $800 \mu \mathrm{g} \mathrm{g}^{-1}$ within this region) to trigger a prominent warning. Moreover, when tested with C927 (ASTM, 2009), the internal volume-normalised concentration of Cd extracted by $4 \%$ acetic acid from the $20 \mathrm{~mm}$ lip area must not exceed $4 \mathrm{mg} \mathrm{L}^{-1}$ (Calderwood and Bopp, 2005). There are no equivalent guidelines provided by the EU, and Poland appears to be the only member state to have its own regulations that stipulate a $0.2 \mathrm{mg}$ limit for $\mathrm{Cd}$ extractable from the lip area in dilute acetic acid (Rebeniak et al., 2014).

\subsubsection{Cadmium pigments in paints}

232

Because of their brilliant shades, $\mathrm{Cd}$ sulphide-based paints have been popular with artists since the mid-19 ${ }^{\text {th }}$ century. The $\mathrm{Cd}$ content of contemporary artists' paints ranges from $12.1 \%$ in acrylics to about $35 \%$ in oil and water-based paints, with the latter having the largest market share (European Chemicals Agency, 2015). In Europe, around 40 tonnes of artists' paints are sold annually, which is equivalent to over $6000 \mathrm{~kg}$ of Cd (Bandow and Simon, 2016).

Cadmium is restricted in consumer paints sold in the European Union to concentrations of $100 \mu \mathrm{g} \mathrm{g}^{-1}$ unless the $\mathrm{Zn}$ content exceeds $10 \%$ ( $\mathrm{Cd}$ is then restricted to a concentration of $1000 \mu \mathrm{g} \mathrm{g}^{-1}$ ) (European Union, 2016). However, unlike plastics, Cd sulphide-based pigments are currently not regulated in artists' paints or the pigments used to directly prepare them. In December 2013, the Swedish Chemicals Agency, KEMI, submitted a proposal to the European Chemicals Agency calling for Cd-based pigments to be restricted in artists' paints on the basis that excess material washed into sewers could contaminate agricultural land through the application of sewage sludge as a fertiliser (European Chemicals Agency, 2013b). However, the ECHA concluded that the risk of exposure was minor and that the input of $\mathrm{Cd}$ to the environment through this source was very small compared with inputs from other sources (European Chemicals Agency, 2015). Subsequent percolation experiments performed using soil amended with sludge and spiked with $\mathrm{Cd}$ pigments also confirmed that the solubility of pigment-bound $\mathrm{Cd}$ was low and that $\mathrm{Cd}$ pigments did not lead to an increase in leachable or bioavailable Cd in soil (Bandow and Simon, 2016).

The human exposure to $\mathrm{Cd}$ evaluated above is indirect (via the contamination of wastewater, sewage sludge, agricultural soil and crops) and is averaged for the general population. However, $\mathrm{Cd}$ exposure restrictions listed in Table 1 largely relate to or imply direct exposure to the consumer through handling of a product (e.g., toys, jewellery, ceramics, decorated glassware) and ingestion of the metal. Thus, although artists' paints constitute a small (but growing) proportion of Cd pigment use, artists themselves are subject to more direct risk of exposure through preparing and handling materials and contaminating hands, clothing and food. The bioaccessibility of $\mathrm{Cd}$ in paints via 
ingestion does not appear to have been studied directly but it would be reasonable to predict greater solubility in the more acidic environment of the human stomach than that of rainwater used to simulate leaching from agricultural soils. Specifically, speciation calculations performed by Bandow and Simon (2016) demonstrate that the solubility of CdS increases exponentially with decreasing $\mathrm{pH}$ such that well over $10 \%$ of $\mathrm{Cd}$ could be mobilised under the conditions typical of the stomach. Thus, for an artists' paint containing $35 \% \mathrm{Cd}$ whose bioaccessibility is $10 \%$, ingestion of only 5 to $6 \mathrm{mg}$ of paint could be equivalent to the weekly tolerable intake of $\mathrm{Cd}$ of an adult of 50 to $60 \mathrm{~kg}\left(2.5 \mu \mathrm{kg}^{-1}\right.$; EFSA panel on contaminants in the food chain, 2011).

\section{Measurement of cadmium and cadmium migration in consumer products}

Cadmium and other elements may be determined rapidly and non-destructively in consumer products, including plastics, ceramics, paints and enamels, by portable x-ray fluorescence (XRF) spectrometry. To this end, the author has analysed an extensive number of samples as part of research into antimony and bromine in household plastics (Turner and Filella, 2017a; 2017b), hazardous elements in children's toys (Turner, 2018b), and metals in decorated glass enamels (Turner, 2018a). Here, data for Cd (and Se) in these samples are synthesised, and additional samples, including household ceramics and beverage bottles, have been analysed for the specific purposes of the current paper.

Briefly, a broad range of commonly used plastic, glass and ceramic consumer products were borrowed from or supplied by various local households, offices, nurseries and schools, or were purchased new or second-hand from different retail outlets (including hardware stores, gift shops, supermarkets and charity shops). Samples (whole products or distinctive components or regions thereof, like different parts of a toy, puzzle, tool or appliance, or different coloured areas of ceramics or enamelled glass) were analysed using a Niton XLT3 He GOLDD+ portable XRF that was deployed in situ and with appropriate shielding or in the laboratory and nose-upwards in a tungsten-lined accessory stand. Counting was performed in a standard-less plastics mode for $30 \mathrm{~s}$ to $1 \mathrm{~min}$, comprising periods equally distributed between two different energy ranges ( $40 \mu \mathrm{A}$ and $50 \mathrm{KVp}$, and $100 \mu \mathrm{A}$ and $20 \mathrm{KVp}$ ). For plastics, a thickness correction was applied after the thickness of the measurement area was measured or estimated, while for ceramics and for enamels on glassware and painted surfaces, respective thicknesses of $0.1 \mathrm{~mm}$ or $0.05 \mathrm{~mm}$ were assumed. For quality assurance purposes, two polyethylene reference discs (PN 180-619, LOT\#T-18, Cd $=292 \pm 20 \mu \mathrm{g} \mathrm{g}^{-1}$ and $\mathrm{Se}=207 \pm 15 \mu \mathrm{g} \mathrm{g}^{-1}$; PN 180-554, batch SN PE-071-N, Cd = $150 \pm 6 \mu \mathrm{g} \mathrm{g}^{-1}$ ) were analysed at regular intervals throughout each measurement session. Data, as spectra and concentrations in $\mu \mathrm{g} g$ 
${ }^{1} \pm 2 \sigma$, were downloaded to a laptop using Niton data transfer software. Detection limits under these conditions (as $3 \sigma$ ) varied inversely with sample thickness and ranged from about 15 to $150 \mu \mathrm{g}$ $\mathrm{g}^{-1}$ for $\mathrm{Cd}$ in plastics and from about 150 to $400 \mu \mathrm{g} \mathrm{g}^{-1}$ for $\mathrm{Cd}$ in ceramics, paints and enamels; detection limits for Se were more variable, with respective ranges of about 12 to $250 \mu \mathrm{g} \mathrm{g}^{-1}$ and 50 to $500 \mu \mathrm{g} \mathrm{g}^{-1}$.

The migration of $\mathrm{Cd}$ was determined in selected products according to appropriate methodologies. Specifically, various colourful components of old toys, games and puzzles were extracted in $0.07 \mathrm{M}$ $\mathrm{HCl}$ according to EN 71-3 (BSI, 1995), while ceramics and decorated glassware were extracted in acetic acid according to Directive 84/500/EEC (Council of the European Communities, 1984) and various, but standardised, modifications. Extracts arising from these tests were analysed by inductively coupled plasma-mass spectrometry or inductively coupled plasma-optical emission spectrometry under operating conditions defined elsewhere (Turner, 2018b).

302

\section{Cadmium concentrations in consumer products}

\subsection{Plastics}

305

Results arising from the analysis of about 1500 consumer plastic products or components thereof, roughly equally divided among six sample categories, are summarised in Table 2. Overall, $\mathrm{Cd}$ was detected in 111 cases, or in about 7\% of all samples tested. In the food-contact category, Cd was positive in several black items of food packaging, various components of coffee jugs or presses, a thermos flask lid and a clear plastic drinks bottle, none of which were of PVC construction. Although mean and median concentrations were the lowest among the six categories considered, in three cases concentrations exceeded $100 \mu \mathrm{g} \mathrm{g}^{-1}$ and would, therefore, be non-compliant according to various regulations or directives (Table 1). In the construction-storage category, Cd was detected across a wider range of colours and at more variable concentrations. Concentrations below $100 \mu \mathrm{g}$

${ }^{1}$ were largely restricted to black products, including a shampoo bottle cap, a clothes hanger and a castor, with the highest concentrations encountered in white PVC door and window frames and in brightly coloured items that included an orange ballcock float. Regarding the clothing-accessory category, $\mathrm{Cd}$ was only detected in items of (mainly black) non-PVC-based plastic jewellery, including beads, a pendant, an earring and, at 35,000 $\mu \mathrm{g} \mathrm{g}^{-1}$, a brooch.

Cadmium was most frequently detected in the toys-hobbies category and across a wide range of products and colours. Here, PVC products that contained detectable Cd (and at concentrations ranging from 38 to $770 \mu \mathrm{g} \mathrm{g}^{-1}$ ) included the black wheels and tracks of several toy vehicles, orange 
and red rubber ducks, and a number of model dinosaurs of various colours. Concentrations of Cd above $1000 \mu \mathrm{g} \mathrm{g}^{-1}$ were, however, restricted to an abundance of old, brightly coloured (and mainly yellow or red) non-PVC-based components of toys, games and puzzles. In the office-garden category, Cd was most commonly encountered in black tool handles, but concentrations above a few hundred $\mu \mathrm{g} \mathrm{g}^{-1}$ were found in a black PVC tool wallet, the black body of a strapped document carrier and the black frame of a chair, with the highest concentration $\left(13,400 \mu \mathrm{g} \mathrm{g}^{-1}\right)$ returned for the red handle of a staple gun. Cadmium concentrations in the electronic and electrical equipment (EEE) category spanned two orders of magnitude and the metal was present in mainly black, grey and white plastic casings and insulating material, of which one sample (a white wire insulator) was PVC-based.

There is clear evidence of the direct, albeit historic, use of Cd as a stabiliser in PVC products designed for external exposure (door and window frames) and at concentrations up to about $1 \%$ by weight. However, the presence of $\mathrm{Cd}$ at much lower concentrations in a range of PVC products (but mainly components of toys) suggests that historical PVC may have been recycled and blended into more contemporary consumer goods. Regarding non-PVC-based products, the presence of Cd at concentrations below $100 \mu \mathrm{g} \mathrm{g}^{-1}$ may be attributed to the presence of traces of PVC as a contaminant in other plastics. Alternatively, $\mathrm{Cd}$ may be present in new consumer products through the prohibited (but often unregulated) recycling of waste EEE plastic, where the metal is encountered as a contaminant through its various uses in electrical components and its concentration is restricted (Table 1). This process is a particular problem for black plastics because of the technological difficulties in sorting materials of this colour in the conventional domestic waste stream (Turner, 2018c). Consistent with this assertion, there was a prevalence of small quantities of Cd among black, non-PVC-based samples, as indicated earlier and that included items of jewellery, tool handles, components of toys, bottle tops, clothes hangers and coffee presses.

Also shown in Table 2 are cases in which Cd was suspected as being present in the form of a sulphide or sulphoselenide pigment. Here, articles were distinctively coloured (mainly red-orange-yellow, but occasionally pink or brown) and non-PVC-based, and contained relatively high concentrations of Cd and, often, Se. Overall, 24 coloured samples (or about $10 \%$ of those analysed, and none of them purchased new) appeared to be pigmented by $\mathrm{Cd}$, with the majority of products components of old children's toys that remain in circulation. The concentrations of $\mathrm{Cd}$ and Se in these samples are shown in Table 3, along with the principal colours and, where known, product name, manufacturer and approximate date of original sale; a selection of toys returning the highest concentrations of $\mathrm{Cd}$ is also illustrated in Figure 1. Concentrations of the metal span two orders of magnitude, with a range that is consistent with that reported for Cd-pigmented plastics more generally (Scoullos et al., 2001), and the highest concentrations occur in red and yellow ABS bricks and other components 
from various Lego sets that appear to have been purchased new in the 1970 s. Selenium was only detected in red and orange samples where $C d$ concentrations exceeded $1500 \mu \mathrm{g} \mathrm{g}^{-1}$, and the best fit line of [Cd] versus [Se] forced through the origin $\left(n=8, r^{2}=0.963\right.$; Figure 2$)$ revealed an average mass ratio of $[\mathrm{Cd}]:[\mathrm{Se}]$ of about 6.4 .

\subsection{Ceramics}

A total of 174 XRF measurements were performed on 75 glazed ceramic products purchased in the UK that included mugs, plates, bowls, teapots, jars, egg cups, jugs and items of cutlery of either a single colour or of multiple colours that constituted a repeating pattern, image or motif. Measurements targeted regions of different colour on the same surface or different surfaces or components of the same product (such as the handle, rim, base and interior). Summary statistics for the ceramic analyses, shown in Table 4, indicate that $\mathrm{Cd}$ was detected as a sulphide or sulphoselenide pigment in 87 cases (or in more than $50 \%$ of analyses performed), often under a lead-based glaze, and across all types of product that were sourced both new and second-hand and, where indicated, were manufactured in both Europe and east Asia. The metal was present in coloured areas that were red, orange, yellow, brown, pink, purple and green but not white, black or blue. Selenium was detected with $\mathrm{Cd}$ in 59 cases in which the colour was either red or orange, and the best fit line of $[\mathrm{Cd}]$ versus [Se] forced through the origin $\left(r^{2}=0.751\right.$; Figure 2$)$ indicated an average mass ratio of [Cd]:[Se] of 8.0 and slightly higher than the corresponding ratio for pigmented plastics (see above).

Overall, measured Cd concentrations ranged from about 50 to $40,000 \mu \mathrm{g} \mathrm{g}^{-1}$, with concentrations below $1000 \mu \mathrm{g} \mathrm{g}^{-1}$ usually associated with yellows and greens and concentrations above $5000 \mu \mathrm{g} \mathrm{g}^{-1}$ always returned by shades of red. Significantly, 14 items of hollow-ware (mainly drinking mugs), most of which were purchased new, contained detectable $\mathrm{Cd}$ in the lip area (including the rim) and/or the interior, with concentrations ranging from about 200 to $40,000 \mu \mathrm{g} \mathrm{g} \mathrm{g}^{-1}$; other items where $\mathrm{Cd}$ was detected in regions that would be in direct contact with food included two plates, a ladle, a tea spoon and a storage jar. Regarding California's Proposition 65, a total of 28 products, all of which were drinking mugs, would potentially require a warning label based on a $\mathrm{Cd}$ content exceeding $4800 \mu \mathrm{g} \mathrm{g}^{-1}$ used in the decorative paint and/or a Cd content exceeding $800 \mu \mathrm{g} \mathrm{g}^{-1}$ in the lip area. (Note that, strictly, limit values on total $\mathrm{Cd}$ are based on nitric acid-hydrogen peroxide digestion but for the purposes of the present discussion, non-destructive XRF measurements are assumed to be equivalent.)

\subsection{Decorated glassware}


The presence and concentrations of $\mathrm{Cd}$ in enamelled decorations on drinking glasses (including tumblers, jars, highballs, beer glasses, wine glasses and shot glasses) have been reported in an earlier publication (Turner, 2018a) and are summarised in Table 4 and below. Briefly, Cd was detected in about $70 \%$ of the 197 logos, patterns, text, pictures and cartoons tested on 72 products. Cadmium was often present in association with a lead-based glaze and was detected on both new and second-hand products that had been manufactured in Europe, Turkey and China. Concentrations ranged from a few hundred $\mu \mathrm{g} \mathrm{g}^{-1}$ to about $70,000 \mu \mathrm{g} \mathrm{g}^{-1}$ and although levels were higher than in ceramic products according to any statistical descriptor, decorations were restricted to the exterior of the product and covered a smaller area (typically between 5 and $50 \%$ of the external surface). Although the highest concentrations and greatest occurrence of $\mathrm{Cd}$ was in red and orange enamels, the metal was detected across a wide range of colours tested that included blue, white and black. It was suspected, therefore, that $\mathrm{Cd}$ had additionally been employed as a component of the flux (e.g. as CdO) (Demont et al., 2012). Selenium was also present across a wider range of colours but restricting measurements to shades of red and orange (and minimising interferences from any components of the flux) the average mass ratio of [Cd]:[Se] was about 10.2 based on the best fit line of [Cd] versus [Se] forced through the origin $\left(n=38, r^{2}=0.921\right.$; Figure 2$)$. According to California's Proposition 65, 42 of the tested products, including many targeting children, would potentially require a warning label based on either or both an exceedance of 4800 $\mu \mathrm{g} \mathrm{g}^{-1} \mathrm{Cd}$ in any enamelling and an exceedance of $800 \mu \mathrm{g} \mathrm{g}^{-1} \mathrm{Cd}$ in enamel encroaching into the lip area.

Bottles for alcoholic drinks (e.g. wines, beers, liqueurs, spirits) are frequently externally embossed with enamelled decorations and logos and yet do not appear to have received any attention in respect of the use of heavy metals in the scientific literature. Mention is made of $\mathrm{Cd}$ pigments in brightly-coloured enamels on glass bottles in the European packaging and packaging waste regulations (European Parliament and Council of the EU, 1994), although it is claimed that many major producers have signed a voluntary agreement aiming to phase out use of the metal (BIS, 2015b). In the present study, 18 decorated bottles purchased from national supermarkets were subject to XRF analysis, once the contents had been consumed. The results, summarised in Table 4, reveal that $\mathrm{Cd}$ was detected in 11 out of 36 analyses performed that encompassed various colours on seven individual products; namely, four bottles of wine, a bottle of cider, a bottle of beer and a bottle of advocaat, whose origins were noted as being Australia ( $\times 2)$, South Africa, Spain, Chile, the UK and the Netherlands (a selection of which is illustrated in Figure 3). On the wine bottles, Cd was always associated with $\mathrm{Pb}$, presumably as a component of the flux, and where $\mathrm{Cd}$ was present in red 
enamelled text or decoration, Se was detected; the mean mass ratio of [Cd]:[Se] was about 12 based on the best fit line of [Cd] versus [Se] forced through the origin $\left(n=4, r^{2}=0.947\right.$; Figure 2).

\subsection{Paints}

Two water-mixable oil-based artists' paints (artisan cadmium red light and artisan cadmium red dark; Windsor and Newton) that had been purchased from a national hardware store were analysed as part of this study. The presence of $\mathrm{Cd}$ was not explicitly referred to on the product labels but mention was made in small print that the paints contained a substance known to be carcinogenic by the state of California. Paints were applied to glass slides with a brush and allowed to air-dry in a fume cupboard for 48 hours before being measured by portable XRF as films of thickness $0.05 \mathrm{~mm}$. Cadmium concentrations of over $500,000 \mu \mathrm{g} \mathrm{g}^{-1}$ were returned for both paints, with accompanying concentrations of Se exceeding 50,000 $\mathrm{g} \mathrm{g}^{-1}$. Concentrations of $\mathrm{Cd}$ are greater than the range reported for paints by the European Chemicals Agency (2015) and should be regarded as indicative because it is unlikely that the XRF is calibrated for such high quantities of the metal. Nevertheless, the mass ratios of [Cd]:[Se] of about 10.5 are consistent with those reported for other products pigmented by $\mathrm{Cd}$ and as illustrated in Figure 2.

Although such paints are designed for artists, consumers may encounter $\mathrm{Cd}$-based paints of various colours on oil-, acrylic or water-based paintings that have been purchased or commissioned. As an example, a brightly-coloured oil painting acquired by the author revealed $\mathrm{Cd}$ concentrations of about $40,000 \mu \mathrm{g} \mathrm{g}^{-1}$ in areas painted orange while other colours (purple, pink, green and yellow) appeared to be $\mathrm{Cd}$-free. Cadmium was also present at concentrations up to $5000 \mu \mathrm{g} \mathrm{g}^{-1}$ in the red, decorated areas of glazed products that had been cast and subsequently painted by customers, including children, at commercial ceramic and pottery studios. This affords a more direct, albeit occasional, exposure route of pigmented $\mathrm{Cd}$ paints for members of the public.

A recent, independent study has also revealed that exposure to Cd paint may be significant through painted wooden and steel chopsticks (Zhao et al., 2018). Here, Cd concentrations determined by atomic absorption spectrometry following acid digestion were reported to be as high as $118,000 \mu \mathrm{g}$ $\mathrm{g}^{-1}$ in the decorated support regions of samples purchased on the east Asian market but that may be representative of chopsticks exported farther afield.

\section{Accessibility of $\mathrm{Cd}$ in consumer products}

451 Although the concentrations of $\mathrm{Cd}$ reported above for plastics, ceramics, enamels and paints may be 452 cause for concern, critical to the health impacts of the metal is its accessibility in or migratability 
from the matrix. Specifically, since ingestion and, for young children, mouthing, are likely to be the principal means of exposure, $\mathrm{Cd}$ solubility in digestive fluids or in food will be a key factor in any risk assessment.

\subsection{Plastics}

457 For non-food contact articles, and in particular children's plastic toys pigmented with Cd, it was assumed by manufacturers that health risks were minimal because the fine sulphide or sulphoselenide particulates are protected by an insoluble layer of plastic. However, a British Standards report mentioned by Fowles (1977) suggested that 1\% of Cd could leach from acrylonitrile butadiene styrene (ABS) under simulated acidic stomach conditions. To this end, Fowles (1977) himself investigated more systematically the factors controlling the leaching of $\mathrm{Cd}$ from $\mathrm{ABS}$ that had been impregnated with red CdSe or yellow CdS. Leaching was found to be dependent on the strength of $\mathrm{HCl}$ employed, shaking speed, temperature, the presence of air, and particle size and the means of particle grinding; however, the most important factor in the experiments was the presence or absence of light, compared under a $500 \mathrm{~W}$ photoflood lamp and in a series of darkened, foilwrapped bottles. Thus, under otherwise identical conditions ( $1 \mathrm{~g}$ of 0.1 to $0.5 \mathrm{~mm}$ particles in $25 \mathrm{ml}$ $0.1 \mathrm{M} \mathrm{HCl}$ for $4 \mathrm{~h}$ at $37.5^{\circ} \mathrm{C}$ ), the quantities of $\mathrm{Cd}$ released from red $\mathrm{ABS}$ in light and dark were an order of magnitude different ( $180 \mu \mathrm{g}$ and $16 \mu \mathrm{g}$, respectively); $\mathrm{Cd}$ release from yellow ABS was less sensitive to light, but differences were still clear (112 $\mu \mathrm{g}$ and $45 \mu \mathrm{g}$ in light and dark, respectively). These observations may be attributed to the photosensitivity of both $\mathrm{Cd}$ compounds, and indicate that any meaningful studies on (pigmented) Cd bioaccessibility from plastics must be performed under the exclusion of light. Such empirical studies have formed the basis of the European Union Toy

474 Safety Directive, as outlined above and defined in Table 1.

A recent investigation into the migratability of toxic elements from children's plastic toys revealed that many individual items (components of games or sets) were non-compliant with respect to both the original and recast Toy Safety Directives (Turner, 2018b). Concentrations of migratable Cd, based on data presented in Turner (2018b) and on new measurements performed as part of the current study, are shown for the individual samples, where tested, in Table 3. These measurements reveal non-compliance for the ABS Lego pieces, with a maximum migratable concentration of over $200 \mu \mathrm{g}$ $\mathrm{g}^{-1}$, or just over $1 \%$ of total $\mathrm{Cd}$ as determined by XRF; inadvertent consumption of $100 \mathrm{mg}$ of this material by a child of $8 \mathrm{~kg}$ would be equivalent to its tolerable weekly intake for the metal. On a percentage migration basis, the range of results for Lego are comparable to the range derived by

484 Fowles (1977) for unspecified red and yellow ABS. However, it is conceivable that higher absolute 
concentrations reported in Table 3 may have arisen through aging and partial photo-oxidation of the pigmented particulates.

\subsection{Ceramics}

488

489

490

491

492

493

494

495

496

497

498

499

500

501

502

503

504

505

506

507

508

509

510

511

512

513

514

515

516

The leaching of $\mathrm{Cd}$ from ceramic tableware and cooking ware has been closely monitored in many countries since the early 1970s (Mourareau, 1978), with harmonisation of various different practical approaches resulting in internationally-recognised tests based on extraction in cold, dilute acetic acid. As with the Toy Safety standard, a critical condition of the test, which is not always stipulated clearly and may explain large discrepancies observed in inter-laboratory trials, is that extraction be performed in the dark due to the photosensitivity of $\mathrm{Cd}$ sulphides and sulphoselenide pigments. The release of Cd proceeds via two successive reactions (Halpin et al., 1978): thus, firstly, Cd and other constituents are released from the glaze by acid attack, with some potential release from the underlying crystalline (pigmented) phase; secondly, the crystalline phase is attacked by the acid in a photosensitive reaction. In practice, therefore, Cd extraction will be dependent on factors like storage time, the acidity and opacity of food or drink, and the presence of any oxidants or antioxidants.

Selected samples ( $n=10$ ) that were Cd-positive on the interior surface (or part thereof) as determined by XRF and that were non-compliant with respect to California's Proposition 65 total $\mathrm{Cd}$ limits were extracted according to Directive 84/500/EEC and the results are shown in Table 5. Note that all products satisfying these criteria were items of hollow-ware, and that five products had been used prior to testing. Concentrations of extractable $\mathrm{Cd}$ range from $<0.1 \mu \mathrm{g} \mathrm{L}^{-1}$ to about $15 \mu \mathrm{g} \mathrm{L}^{-1}$ and do not appear to be related to the concentration of total $\mathrm{Cd}$. There is no evidence of elevated concentrations arising from prior usage, but damage to the interior glazing (specifically, a vertical hairline crack) and relatively low firing temperature (for earthenware) appear to accentuate $\mathrm{Cd}$ migration. Cadmium concentrations for all items tested were well below the current $300 \mu \mathrm{g} \mathrm{L}^{-1}$ European limit, but the damaged and earthenware products would be non-compliant according to the new, proposed limit of $5 \mu \mathrm{g} \mathrm{L}{ }^{-1}$ (Beldí et al., 2016).

\subsection{Decorated drinking glasses}

Results arising from the acetic acid extraction of the $20 \mathrm{~mm}$ lip area of drinking glasses are given in Turner (2018a) and summarised as follows. Thus, 16 new and second-hand products were tested for extractable $\mathrm{Cd}$, with interior volume-normalised concentrations ranging from $<10 \mu \mathrm{g} \mathrm{L}^{-1}$ to around $40,000 \mu \mathrm{g} \mathrm{L}^{-1}$ and five items non-compliant according to California's Proposition 65; significantly, concentrations up to about $3000 \mu \mathrm{g} \mathrm{L}^{-1}$ were released by a popular soft drink (Coca Cola Classic). 
Overall, acetic-extractable concentrations were orders of magnitude greater than concentrations released by the acid from ceramic hollow-ware products under equivalent conditions, and for one product (a mug decorated with repeating red rings, illustrated in Figure 3), a single acetic acid test mobilised 40 times the weekly tolerable intake for an adult of $50 \mathrm{~kg}$. Presumably the high mobility of the metal is due to $\mathrm{Cd}$ pigments being incorporated into the frit that is fired and over-glazed at a lower temperature on glassware and, potentially, because there is little (or no) requirement for pigment particle encapsulation by zircon. The latter assertion was explored by comparing spectra of Cd-positive ceramic articles and Cd-enamelled drinking glasses, and as exemplified in Figure 4; thus, in nearly all ceramic products, a distinct zirconium peak $\left(\mathrm{Zr}_{\mathrm{k \alpha}}\right)$ was observed at $15.78 \mathrm{keV}$ that was absent on enamelled glass. Release of crystalline $\mathrm{Cd}$ from decorated glassware is not, therefore, constrained by the erosion of the glaze or zirconium silicate but proceeds directly through acidic attack of the enamel.

Presumably, decorations on glass beverage bottles are subject to the same process of acid attack, given that the décor is not over-glazed and the pigments are not encapsulated by zircon (and as confirmed by examination of XRF spectra). While the handling of decorated bottles is likely to pose minimal risk of $\mathrm{Cd}$ exposure to the consumer, the recycling of such products is a potential source of $\mathrm{Cd}$ contamination of the raw cullet and new glassware.

\section{Discussion and concluding remarks}

This study has illustrated the type of contemporary and historical (non-metallic) consumer goods in which $\mathrm{Cd}$ is present, with the focus on $\mathrm{Cd}$ in the form of pigmented sulphides and sulphoselenides. Small quantities of $\mathrm{Cd}$ appear to be heterogeneously dispersed among consumer plastics, an effect that may be attributed to the recycling and blending of electronic waste and PVC. While typical concentrations reported are within the most recent regulatory limits and are unlikely to pose a significant risk to consumers, the widespread occurrence of the metal highlights the poor and inefficient practices involved in sorting and managing end-of-life products, and in particular plastic housings of electronic equipment (Turner, 2018c).

544 Pigmented Cd was never detected in new plastic goods in the present study. By comparison, analysis

545 of beached plastic litter from south west England reveals a frequent occurrence of brightly coloured 546 (mainly red, orange and yellow) Cd-containing samples including bottle tops, gun cartridges and 547 ropes as well as unidentifiable fragments of varying sizes and shapes (Turner, 2016; Massos and 548 Turner, 2017). This observation is consistent with the incorporation of Cd pigments in single-use 
items and consumer plastics that are no longer in circulation (Hansen et al., 2014). Plastics in which

$550 \mathrm{Cd}$ is most likely to be encountered by the contemporary consumer are brightly coloured components of popular old toys, games and puzzles that have been re-sold or handed down. Here, total $\mathrm{Cd}$ concentrations can be as high as $2 \%$ by weight and migratable concentrations may exceed the current toy safety limit of $17 \mu \mathrm{g} \mathrm{g}^{-1}$ by more than an order of magnitude. Of most concern in this respect are small, mouthable products or components that are designed for young children and that are visibly worn or damaged.

With restrictions on the use of $\mathrm{Cd}$ in plastics, the principal current use of pigmented $\mathrm{Cd}$ is in decorated ceramic products. Although total interior concentrations of the metal on articles designed for food and drink may exceed levels that trigger a California Proposition 65 warning about potential health impacts, standard tests conducted on new products purchased in the UK (but manufactured in various countries and regions) as part of the study indicate that migratable concentrations are well below the current European limit of $300 \mu \mathrm{g} \mathrm{L}^{-1}$. A proposed, significant downward revision of this figure to $5 \mu \mathrm{g} \mathrm{L}^{-1}$, however, will prove more challenging for manufacturers, and especially for those producing earthenware that is fired at relatively low temperatures. The revised limit may also be exceeded more generally should goods become damaged or worn and it is recommended that clear advice is given to consumers about the condition of ceramic items used to store or serve food and drinks. It should also be borne in mind that Cd usually co-exists with other toxic metals in ceramic products (and mainly lead in the glaze) and that there are uncertainties about the suitability of the present testing protocol. With respect to the latter, conducting extractions in the dark when

569 Cd pigments are known to be photosensitive is bound to underestimate $\mathrm{Cd}$ migration and appears to contradict the precautionary approach that is generally advocated (Nawrot et al., 2010).

Despite more limited décor that is restricted to the exterior surfaces, enamelled drinking glasses pose a greater risk of $\mathrm{Cd}$ exposure to consumers, and in particular to children. This is because $\mathrm{Cd}$ pigments fused to glass are considerably more accessible than when sealed on ceramics by glazing.

574 Thus, without zircon encapsulation and a protective layer of glazing, $\mathrm{Cd}$ is subject to direct attack in 575 the painted lip area if an acidic drink is being consumed. Although empirical studies have shown 576 that, for some products, distinct discolouration and even deterioration of the décor may occur 577 (Turner, 2018a), in many cases, and to the consumer, Cd may be mobilised without any obvious 578 visible modification of the enamelled surface. Many bottles used for the storage of drinks are also 579 enamelled with Cd-based pigments and, while not posing a significant risk to consumers, have the potential to contaminate recycled glass products. 
Given the potential health risks associated with externally decorated glass hollow-ware, and especially for articles that target children, it is recommended that further studies focus on the physical and chemical makeup of contemporary enamels and the release of heavy metals therefrom, and that suitable standardised regulations are devised and enforced.

Acknowledgements

The author gratefully acknowledges technical support from Mr Kevin Solman, Dr Andy Fisher and Mr Rupert Goddard (PU). The work was partly funded by a HEIF Plymouth Marine Institute Grant.

\section{References}

591

592

593

594

595

596

597

598

599

600

601

602

603

604

605

606

607

608

609

610

611

612

613

614

ASTM, 2009. Standard test method for lead and cadmium extracted from the lip and rim area of glass tumblers externally decorated with ceramic glass enamels. C927-80(2009), ASTM International.

ASTM, 2016. Standard test method for lead and cadmium extracted from glazed ceramic surfaces. C738-94(2016), ASTM International.

Bandow, N., Simon, F.-G., 2016. Significance of cadmium from artists' paints to agricultural soil and the food chain. Environmental Sciences Europe 28, 12: DOI 10.1186/s12302-016-0077-6

Beldì, G., Jakubowska, N., Peltzer, M.A., Simoneau, C., 2016. Testing approaches for the release of metals from ceramic articles: In support of the revision of the Ceramic Directive 84/500/EEC. Publications Office of the European Union, Luxembourg, 86pp.

BIS, 2011. RoHS Regulations: Government Guidance Notes. Department for Business, Innovation and Skills URN 11/526, 38pp.

BIS, 2015a. Batteries Regulations Amendment: Impact Assessment. Department for Business, Innovation and Skills https://www.legislation.gov.uk/ukia/2015/50/pdfs/ukia 20150050 en.pdf (accessed 6/18).

BIS, 2015b. Packaging (Essential Requirements) Regulations: Government Guidance Notes. Department for Business, Innovation and Skills https://assets.publishing.service.gov.uk/government/uploads/system/uploads/attachment data/file 4460891/BIS-15-460-packaging-essential-requirements-regulations-gov-guidance-notes.pdf (accessed 12/18)

BSI, 1995. Safety of Toys - Part 3: Migration of Certain Elements. British Standard BS EN 71-3:1994, London.

Calderwood, J.A., Bopp, A., 2005. Summary of California Proposition 65 Settlement Related to Lead and Cadmium Exposure from Outside Surfaces of Glass and Ceramicware. Society of Glass and Ceramic Decorators, Alexandria, VA, 7pp. 
615 Canadian Minister of Justice, 2018. Children's Jewellery Regulations, SOR/2018-82. http://laws-

616 lois.justice.gc.ca/PDF/SOR-2018-82.pdf (accessed 6/18)

617 Chemsec, 2018. 'Substitute It Now!' list, searched 6/18

618 http://sinlist.chemsec.org/search/search?query=cadmium+sulphide

619 Council of the European Communities, 1984. Council Directive of 15 October 1984 on the

620 approximation of the laws of the Member States relating to ceramic articles intended to come into

621 contact with foodstuffs (84/500/EEC). Official Journal of the European Communities No L 277/12.

622 Council of the European Communities, 1988. Council Directive of 3 May 1988 concerning the safety

623 of toys (88/378/EEC). Official Journal of the European Communities No L 187/1.

624 Demont, M., Boutakhrit, K., Fekete, V., Bolle, J., Van Loco, J., 2012. Migration of 18 trace elements

625 from ceramic food contact material: Influence of pigment, $\mathrm{pH}$, nature of acid and temperature. Food

626 and Chemical Toxicology 50, 734-743.

627 Department of Toxic Substances Control, 2012. California's Metal-Containing Jewelry Law.

628 https://www.dtsc.ca.gov/HazardousWaste/Jewelry/upload/Jewelry-Fact-Sheet.pdf

629 (accessed 6/18).

630 EFSA panel on contaminants in the food chain, 2011. Scientific opinion statement on tolerable 631 weekly intake for cadmium. European Food Standards Authority Journal 9, 1-19.

632 European Chemicals Agency, 2012. The use of cadmium and its compounds in articles coloured for 633 safety reasons (Derogation in paragraph 3 of entry 23 of Annex XVII). ECHA, Helsinki.

634 European Chemicals Agency, 2013a. Europe considers total ban on cadmium in plastics. Additives for 635 Polymers 2013, 10-11.

636 European Chemicals Agency, 2013b. Annex XV Restriction Report: Proposal for a Restriction -

637 Cadmium and its Compounds in Artists' Paints. ECHA, Helsinki, 197pp.

638 European Chemicals Agency, 2015. Committee for Risk Assessment (RAC) and Committee for Socio639 economic Analysis (SEAC): Opinion on an Annex XV dossier proposing restrictions on cadmium and 640 its compounds in artist's paints. ECHA, Helsinki, 31pp.

641 European Parliament and Council, 2003. Directive 2002/95/EC on the restriction of the use of certain 642 hazardous substances in electrical and electronic equipment. Official Journal of the European Union 643 L37/19.

644 European Parliament and of the Council, 2006. Directive 2006/66/EC of 6 September 2006

645 on batteries and accumulators and waste batteries and accumulators and repealing Directive

$64691 / 157 /$ EEC. Official Journal of the European Union L266/1.

647

648 European Parliament and Council of the EU, 1994. Directive 94/62/EC of 20 December 1994 on 649 packaging and packaging waste. Official Journal of the European Union L365.

650 
European Parliament and Council of the EU, 2009. Directive 2009/48/EC of the European Parliament and of the Council of 18 June 2009 on the safety of toys. Official Journal of the European Union

$653 \mathrm{~L}$ L170/1.

654 European Union, 2011. Commission Regulation (EU) No. 494/2011 amending Regulation (EC) No

$6551907 / 2006$ of the European Parliament and of the Council on the Registration, Evaluation,

656 Authorisation and Restriction of Chemicals (REACH) as regards Annex XVII (Cadmium). Official

657 Journal of the European Union L134/2.

658 European Union, 2016. Commission Regulation (EU) 2016/217 amending Annex XVII to Regulation

659 (EC) No 1907/2006 of the European Parliament and of the Council concerning the Registration,

660 Evaluation, Authorisation and Restriction of Chemicals (REACH) as regards cadmium. Official Journal

661 of the European Union L40/5.

662 Fowles, G.W.A., 1977. The leaching of cadmium from plastic toys. Science of the Total Environment

663 7, 207-216.

664 Guney, M., Zagury, G.J., 2014. Bioaccessibility of $\mathrm{As}, \mathrm{Cd}, \mathrm{Cu}, \mathrm{Ni}, \mathrm{Pb}$, and Sb in toys and low-cost

665 jewelry. Environmental Science and Technology 48, 1238-1246.

666 Halpin, M.K., Carroll, D.M., Burns, D., Toal, J., 1978. The release of cadmium from ceramic tableware

667 towards a method of test. In: Third International Symposium on Ceramics: Proceedings of the

668 Session on Lead and Cadmium Release from Ceramic Glazes. Commission of the European

669 Communities EUR 5956, Brussels, pp. 48-68.

670 Hansen, E., Nilsson, N., Vium, K.S.R., 2014. Hazardous Substances in Plastics. The Danish

671 Environment Protection Agency, Copenhagen, 182pp.

IEEE, 2006. Standard for environmental assessment of personal computer products, including laptop personal computers, desktop personal computers, and personal computer monitors. The Institute of Electrical and Electronics Engineers Inc, New York, 32pp.

Kawasaki, T. Kono, K., Dote, T., Usuda, K., Shimizu, H., Dote, E., 2004. Markers of cadmium exposure in workers in a cadmium pigment factory after changes in the exposure conditions. Toxicology and Industrial Health 20, 51-56.

678 Larsson, S.C., Wolk, A., 2015. Urinary cadmium and mortality from all causes, cancer and 679 cardiovascular disease in the general population: systematic review and meta-analysis of cohort studies. International Journal of Epidemiology 45, 782-791.

681 Lehman, R., 2002. Lead Glazes for Ceramic Foodware. The International Lead Management Center, 682 Research Triangle Park, NC, 193pp.

683 Liu, H., Gao, H., Long, M., Fu, H., Alvarez, P.J.J., Li, Q., Zheng, S., Qu, X., Zhu, D., 2017. Sunlight 684 promotes fast release of hazardous cadmium from widely-used commercial cadmium pigments. 685 Environmental Science and Technology 51, 6877-6886.

686 Massos, A., Turner, A., 2017. Cadmium, lead and bromine in beached microplastics. Environmental 687 Pollution 227, 139-145.

688 Mourareau, R., 1978. Harmonization in the European Community of the regulations on the 689 extraction of toxic metal elements from ceramic articles. In: Third International Symposium on 690 Ceramics: Proceedings of the Session on Lead and Cadmium Release from Ceramic Glazes.

691 Commission of the European Communities EUR 5956, Brussels, pp. 7-16. 
Nawrot, T.S., Staessen, J.A., Roels, H.A., Munters, E., Cuypers, A., Richart, T., Ruttens, A., Smeets, K., Clijsters, H., Vangronsveld, J., 2010. Cadmium exposure in the population: from health risks to strategies of prevention. BioMetals 23, 769-782.

Office of Environmental Health Hazard Assessment, 2016. Proposition 65: The Safe Drinking Water and Toxic Enforcement Act of 1986. California Environmental Protection Agency https://oehha.ca.gov/proposition-65 (accessed June 2018).

Olesen, A., Hoshiko, E., 2010. An open secret: Chinese manufacturers use toxic cadmium in jewelry despite health risks. Globalization Monitor http://www.globalmon.org.hk/content/open-secretchinese-manufacturers-use-toxic-cadmium-jewelry-despite-health-risks (accessed 5/18).

Pfaff, G., 2017. Inorganic Pigments. Walter De Gruyter, Berlin. 329pp.

Rebeniak, M., Wojciechowska-Mazurek, M., Mania, M., Szynal, T., Strzelecka, A., Starska, K., 2014. Exposure to lead and cadmium released from ceramics and glassware intended to come into contact with food. Roczniki Państwowego Zakładu Higieny 65, 301-309.

Satarug, S., 2012. Long-term exposure to cadmium in food and cigarette smoke, liver effects and hepatocellular carcinoma. Current Drug Metabolism 13, 257-271.

Scoullos, M.J., Vonkeman, G.H., Thornton, I., Makuch, Z., 2001. Mercury - Cadmium - Lead: Handbook for Sustainable Metals - Policy and Regulation. Springer, Dordrecht, 524pp.

Turner, A., 2016. Hazardous metals, metalloids and other elements in marine litter. Marine Pollution Bulletin 111, 136-142.

Turner, 2018a. High levels of migratable lead and cadmium on decorated drinking glassware. Science of the Total Environment 616-617, 1498-1504.

Turner, 2018b. Concentrations and migratabilities of hazardous elements in second-hand children's plastic toys. Environmental Science and Technology 52, 3110-3116.

Turner, 2018c. Black plastics: Linear and circular economies, hazardous additives and marine pollution. Environment International 117, 308-318.

Turner, A., Filella, M., 2017a. Field-portable-XRF reveals the ubiquity of antimony in plastic consumer products. Science of the Total Environment 584-585, 982-989.

Turner, A., Filella, M., 2017b. Bromine in plastic consumer products - Evidence for the widespread recycling of electronic waste. Science of the Total Environment 601-602, 374-379.

US Consumer Product Safety Commission, 2018. Toy Safety Standard ASTM F963-17 https://www.cpsc.gov/Business--Manufacturing/Business-Education/Toy-Safety accessed 6/18.

Waalkes, M.P., 2003. Cadmium carcinogenesis. Mutation Research/Fundamental and Molecular Mechanisms of Mutagenesis 533, 107-120.

Weidenhamer, J.D., Miller, J., Guinn, D., Pearson, J., 2011. Bioavailability of cadmium in inexpensive jewelry. Environmental Health Perspectives 119, 1029-1033.

WHO, 2010. Exposure to Cadmium: A Major Public Health Concern. World Health Organization, Geneva, Switzerland. 
729 WHO, 2011. Cadmium in Drinking Water - Background Document for Development of WHO

730 Guidelines for Drinking-Water Quality. World Health Organization, Geneva, Switzerland.

731 Wilson, D.C., Young, P.J., Hudson, B.C., Baldwin, G., 1982. Leaching of cadmium from pigmented 732 plastics in a landfill site. Environmental Science and Technology 16, 560-571.

733 Zhao, Di., Juhasz, A.L., Luo, J., Li, H.-B., Ma, L.Q., 2018. Metals in paints coated on chopsticks:

734 solubilization in simulated salvia, gastric, and food solutions and implication for human health.

735 Environmental Research 167, 299-306. 
Table 1: Regulations relevant to the use of cadmium in consumer goods.

\begin{tabular}{|c|c|c|c|}
\hline Regulation/Directive & Product type & Permissible Cd & Reference \\
\hline Directive 2006/66/EC & Batteries and accumulators & New Ni-Cd batteries only permitted in certain applications & European Parliament and of the Council (2006) \\
\hline Directive 2002/95/EC & Electrical and electronic equipment & $<100 \mu \mathrm{g} \mathrm{g}^{-1}$ in any (plastic) component of new equipment & European Parliament and Council (2003) \\
\hline IEEE Standard 1680 & Personal computers & $<50 \mu \mathrm{g} \mathrm{g}^{-1}$ in any homogenous material & IEEE (2006) \\
\hline \multirow[t]{2}{*}{ Regulation 494/2011 } & Jewellery & $<100 \mu \mathrm{g} \mathrm{g}^{-1}$ for new products & European Union (2011) \\
\hline & Plastic consumer products & $<100 \mu \mathrm{g} \mathrm{g}^{-1}$ for new products ${ }^{a}$ & \\
\hline Directive 88/378/EEC & Toys & $<50 \mu \mathrm{g} \mathrm{g}^{-1}$ migratable $\mathrm{Cd}$ & Council of the European Communities (1988) \\
\hline Directive 2009/48/EC & Plastic toys & $<23 \mu \mathrm{g} \mathrm{g}^{-1}\left(\right.$ now $\left.<17 \mu \mathrm{g} \mathrm{g}^{-1}\right)$ migratable $\mathrm{Cd}$ & European Parliament and Council of the EU (2009) \\
\hline Children's Jewellery Regulations & Jewellery & $<130 \mu \mathrm{g} \mathrm{g}^{-1}$ & Canadian Minister of Justice (2018) \\
\hline Metal-Containing Jewelry Law & Jewellery & $<300 \mu \mathrm{g} \mathrm{g}^{-1}$ & Department of Toxic Substances Control (2012) \\
\hline ASTM F963-17 & Toys & $<75 \mu \mathrm{g} \mathrm{g}^{-1}$ migratable $\mathrm{Cd}$ & US Consumer Product Safety Commission (2018) \\
\hline \multirow[t]{2}{*}{ Directive 84/500/EEC } & Cooking ware ceramics & $<100 \mu \mathrm{g} \mathrm{L}^{-1}$ migratable $\mathrm{Cd}$ & Council of the European Communities (1984) \\
\hline & Hollow-ware ceramics & $<300 \mu \mathrm{g} \mathrm{L}^{-1}$ migratable $\mathrm{Cd}$ & \\
\hline California Proposition 65 & Lip area of ceramics and glassware for food & $<800 \mu \mathrm{g} \mathrm{g}^{-1}$ & Office of Environ. Health Hazard Assess (2016) \\
\hline Regulation 2016/217 & Consumer paints & $<100 \mu \mathrm{g} \mathrm{g}^{-1}$ or $<1000 \mu \mathrm{g} \mathrm{g}^{-1}($ where $\mathrm{Zn}>10 \%)$ & European Union (2016) \\
\hline Directive 94/62/EC & Packaging and packaging waste & $<100 \mu \mathrm{g} \mathrm{g}^{-1 \mathrm{~b}}$ & European Parliament and Council of the EU (1994) \\
\hline
\end{tabular}

a Except where coloured for safety or where recycled PVC used

${ }^{\mathrm{b}}$ The limit applies to the sum of $\mathrm{Cd}, \mathrm{Hg}, \mathrm{Pb}$ and $\mathrm{Cr} \mathrm{VI}$ concentrations, except for recycled materials in controlled, closed loop products 
Table 2: Number of cases in which $\mathrm{Cd}$ was detected among the different categories of plastic consumer products and components tested by XRF, along with summary statistics defining its concentration (in $\mu \mathrm{g} \mathrm{g}^{-1}$ ). Also shown are the occurrence of Cd in PVC-based plastic samples and its (suspected) presence in pigmented form.

\begin{tabular}{|c|c|c|c|c|c|c|c|}
\hline Descriptor & Food-contact & Storage and construction & Clothing and accessories & Toys and hobbies & Office and garden & EEE & Total \\
\hline$n$ & 10 & 17 & 9 & 43 & 12 & 20 & 111 \\
\hline mean & 79.6 & 1670 & 4100 & 3270 & 1490 & 266 & 2050 \\
\hline median & 67.5 & 488 & 124 & 407 & 358 & 153 & 209 \\
\hline $\min$ & 27.2 & 18.6 & 35.3 & 36.3 & 21.1 & 18.8 & 18.6 \\
\hline $\max$ & 148.4 & 10,000 & 35,000 & 19,600 & 13,400 & 1,370 & 35,000 \\
\hline$n$ PVC & 0 & 5 & 0 & 10 & 1 & 1 & 17 \\
\hline$n$ pigmented & 0 & 2 & 0 & 21 & 1 & 0 & 24 \\
\hline
\end{tabular}




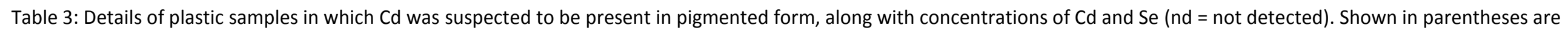
concentrations of migratable Cd determined according to European Standard EN 71-3.

\begin{tabular}{|c|c|c|c|c|c|c|}
\hline product & sample & colour & manufacturer & date & $\mathrm{Cd}, \mu \mathrm{gg}^{-1}$ & Se, $\mu g^{-1}$ \\
\hline ballcock & float valve & orange & Ideal Standard & 1970s & 2360 & 189 \\
\hline stapler & handle & red & unknown & $1990 \mathrm{~s}$ & 13,400 & 3360 \\
\hline Venetian blind & slat & red-brown & unknown & unknown & 8,221 & 905 \\
\hline "Mousey Mousey" & games cup & orange & Spears & 1983 & $2470(0.83)$ & 335 \\
\hline "Connect 4" & counter & red & MB Games & 1984 & $2500(6.6)$ & 632 \\
\hline Shape sorter & shape & yellow & Tupperware & $1970 \mathrm{~s}$ & 8950 (10.2) & nd \\
\hline \multirow[t]{2}{*}{ "Sorry" board game } & figure & yellow & Waddingtons & 1970s & 2060 & nd \\
\hline & figure & red & & & 1120 & nd \\
\hline \multirow[t]{2}{*}{ "Weebles" } & figure & red & Airfix & 1970s & 1950 & 420 \\
\hline & figure & pink & & & 592 & nd \\
\hline \multirow[t]{7}{*}{ various construction sets } & brick & yellow & Lego & $1970 \mathrm{~s}$ & $15600(61.7)$ & nd \\
\hline & brick & yellow & & & 8940 & nd \\
\hline & brick & red & & & $19600(221)$ & 2920 \\
\hline & brick & red & & & $16300(145)$ & 2700 \\
\hline & brick & yellow & & & $13500(98.0)$ & nd \\
\hline & brick & yellow & & & 17400 & nd \\
\hline & $\operatorname{cog}$ & yellow & & & 12100 & nd \\
\hline "Smurf" set & figure & red & Schleich & 1979 & $648(30.5)$ & nd \\
\hline \multirow[t]{2}{*}{ "Playmobil" set } & figure & yellow & Geobra Brandstaetter & 1974 & 8693 (33.3) & nd \\
\hline & stretcher & red & & & 242 & nd \\
\hline bucket & bucket handle & red & unknown & unknown & 2310 & 538 \\
\hline \multirow[t]{2}{*}{ construction kit } & figure & yellow & unknown & unknown & 303 & nd \\
\hline & figure & orange & & & 236 & nd \\
\hline
\end{tabular}


Table 4: Number of cases in which Cd was detected by XRF in the glaze of ceramics and in the enamels of decorated drinking glasses and decorated glass bottles, along with summary statistics defining its concentration (in $\mu \mathrm{g} \mathrm{g}^{-1}$ ).

\begin{tabular}{lccc}
\hline & $\begin{array}{c}\text { Ceramics } \\
(n=174)\end{array}$ & $\begin{array}{c}\text { Drinking glassware } \\
(n=197)\end{array}$ & $\begin{array}{c}\text { Glass bottles } \\
(n=36)\end{array}$ \\
\hline$n$ & 87 & 134 & 11 \\
mean & 4420 & 11,400 & 6490 \\
median & 2920 & 8460 & 5670 \\
min & 46.6 & 285 & 1170 \\
max & 38,100 & 70,900 & 19,400 \\
\hline
\end{tabular}

Table 5: Concentrations of total (interior) and extractable Cd in various items of hollow ware tested according to Directive 84/500/EEC. All volumes are approximately $350 \mathrm{ml}$ except where noted and asterisks denote products that had been used before testing.

\begin{tabular}{|c|c|c|c|}
\hline Type and interior colour(s) & Retailer/supplier & Cd-total, $\mu \mathrm{g} \mathrm{g}^{-1}$ & Cd-extractable, $\mu \mathrm{g} \mathrm{L}^{-1}$ \\
\hline mug with spoon, red* & promotional gift & 6070 & 0.32 \\
\hline mug, orange* & department store & 2950 & 0.36 \\
\hline mug, orange-brown & hardware store & 2700 & 0.05 \\
\hline stoneware mug, orange-brown & hardware store & 1120 & 0.41 \\
\hline bone China mug, red-white (damaged)* & gift store & 3770 & 7.29 \\
\hline mug, yellow* & gift store & 1130 & 2.72 \\
\hline mug, red & supermarket & 2920 & 1.82 \\
\hline mug, red & supermarket & 4070 & 0.25 \\
\hline earthenware jug, brown (500 ml)* & secondhand store & 38100 & 14.9 \\
\hline mug, red & supermarket & 2890 & 0.01 \\
\hline
\end{tabular}




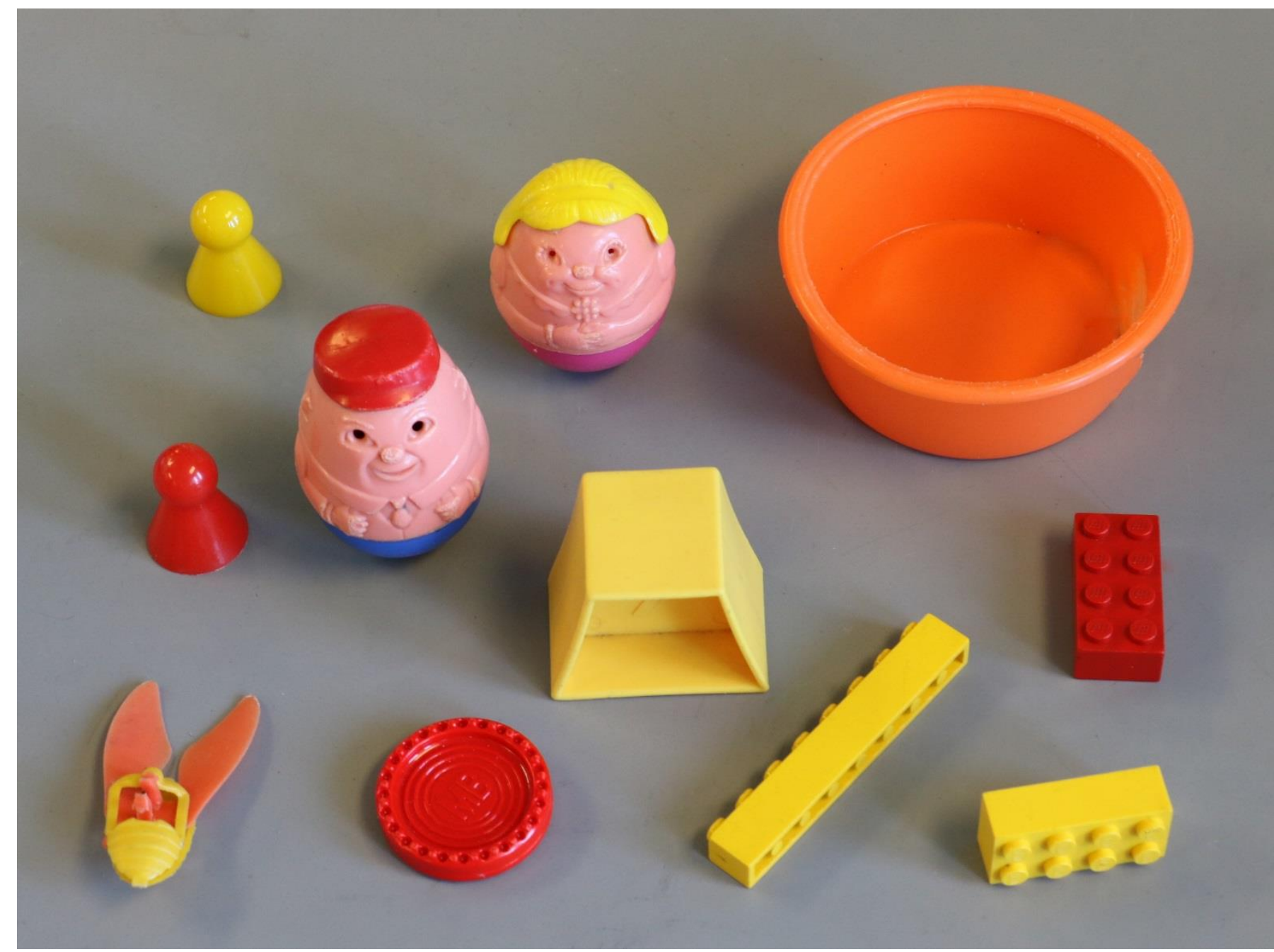


Figure 2: Concentrations of $\mathrm{Cd}$ versus concentrations of Se in different types of consumer product. Statistical results are derived from linear regression analysis (forced through the origin) of individual datasets and overall data; note that $p<0.01$ in all cases.

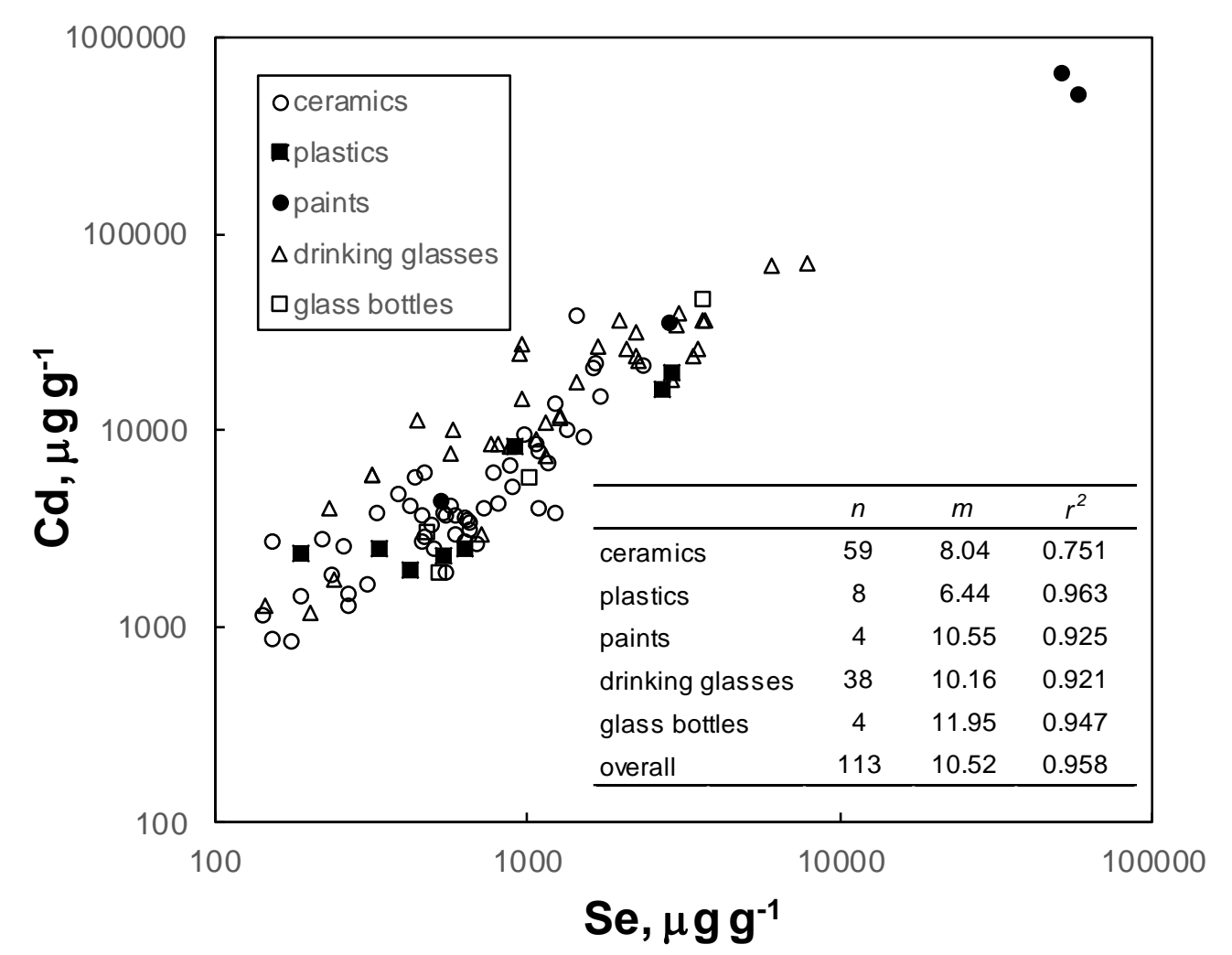


Figure 3: A selection of Cd-positive ceramic mugs and decorated drinking glasses and bottles analysed as part of the present study.

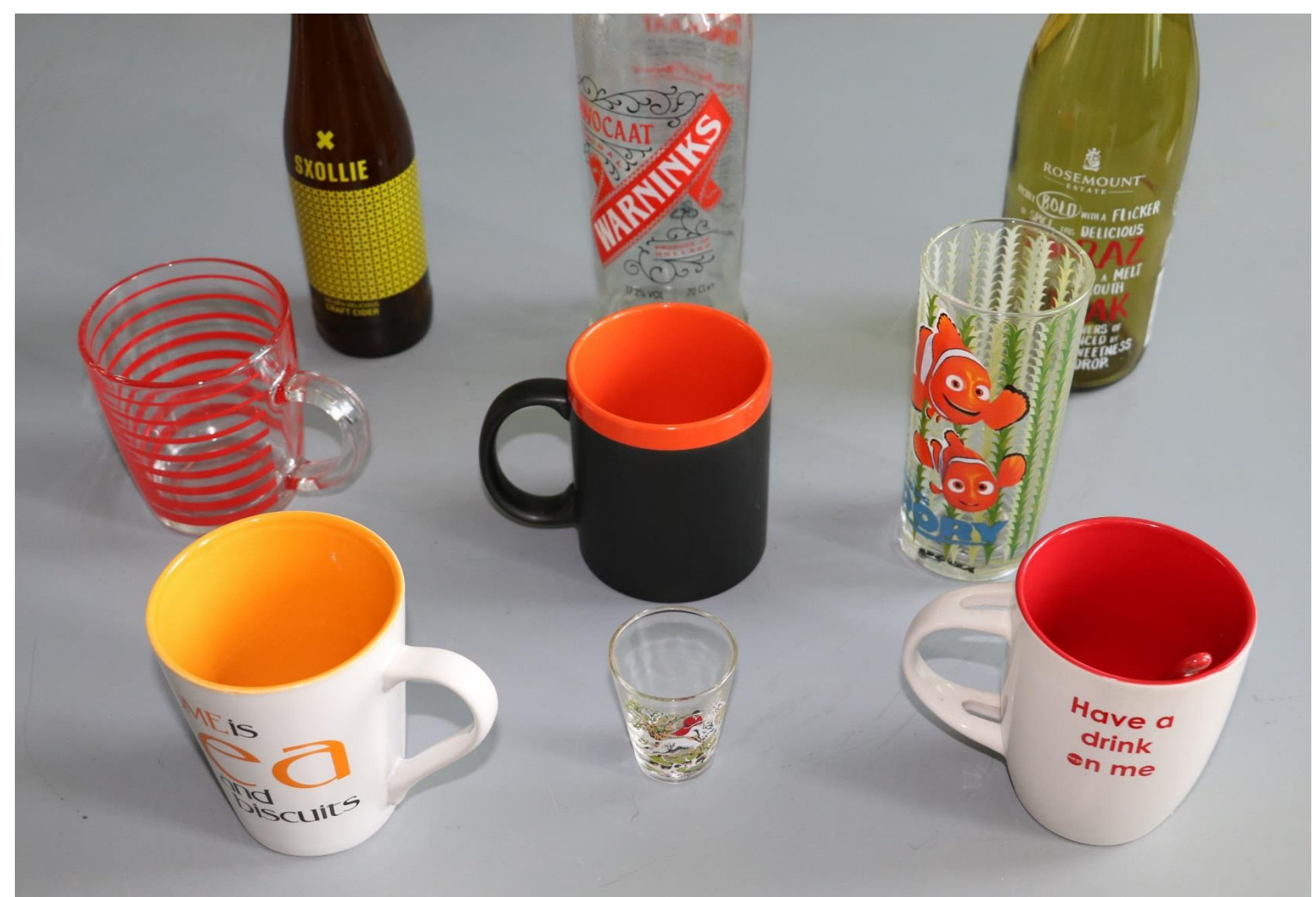


Figure 4: Spectra arising from the analysis of externally decorated areas (located in yellow) of a ceramic mug and high ball glass. Note the absence of the Zrk $\mathrm{r}_{\mathrm{k}}$ peak on the glass, indicating no encapsulation of pigmented $\mathrm{Cd}$ sulphoselenide.
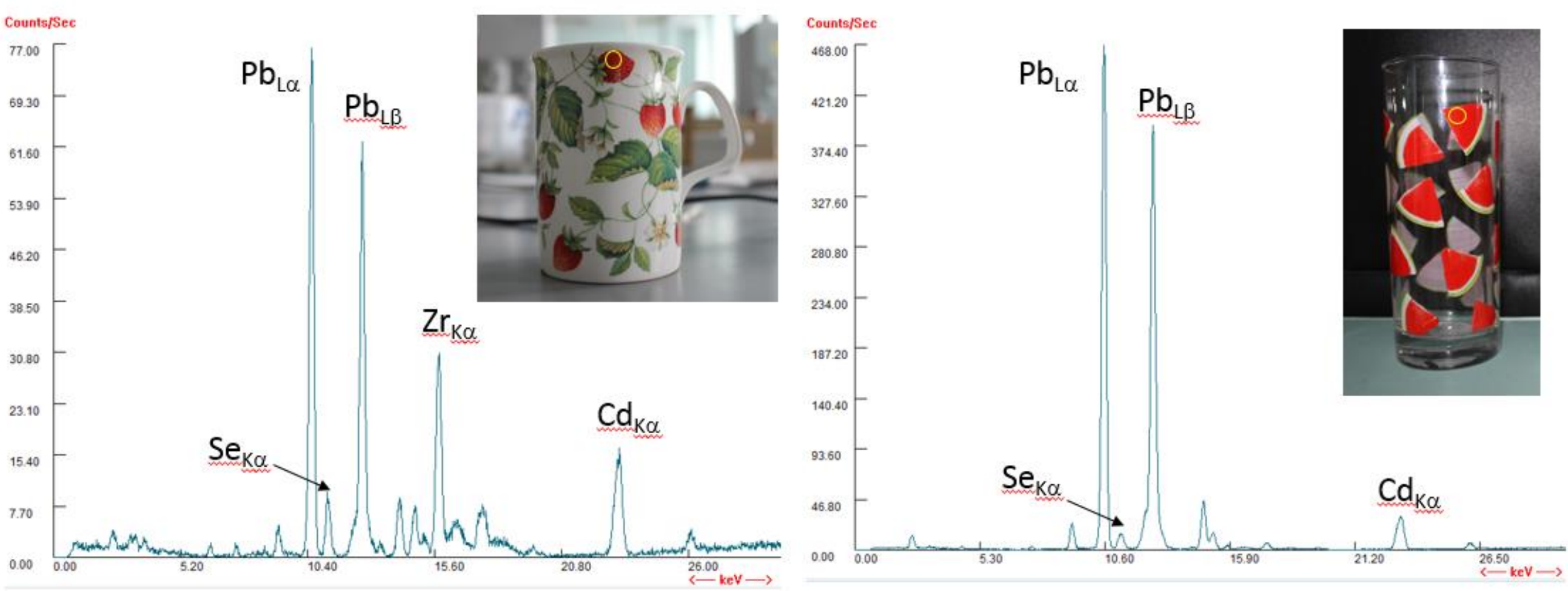